\title{
Vox Populi, Vox Dei; or Measuring the "Goodness" of College Libraries: A Case Study
}

\author{
Plummer Alston Jones, Jr.
}

The history of the development and implementation of college library standards and, indeed, the college library accreditation process in general represent two of the more exasperating chapters in the saga of academic librarianship. ${ }^{1}$ While there is wholehearted agreement within the college library community that colleges should have "good" libraries, there are at least three proponents of college libraries, in addition to college librarians themselves, who have a vested interest in determining how to measure "goodness" - funding bodies, state and regional accrediting agencies, and professional library associations, the collective vox dei of the academic community.

Of these three groups, only the professional library associations and, to a lesser extent, funding bodies have espoused quantitative as well as qualitative standards. Regional and state accrediting agencies have lobbied quite vigorously and effectively in the past for purely qualitative standards, viewed as more flexible and thus more applicable to a wider range of institutions. More recently, however, there has been a noticeable trend among regional accrediting agencies, notably the Southern Association of Colleges and Schools (SACS), toward standards calling for "educational outcomes assessment" which in itself implies the need for quantifiable data. ${ }^{2}$

Where are these quantifiable data to be found? One obvious source is library use statistics collected in various categories which represent in objective numerical terms the use and amounts of library resources and services. While the categories of statistics may well vary from college to college, all North Carolina college libraries presumably keep statistics in categories called for in the annual North Carolina Higher Education Data

Plummer Alston Jones, Jr., is Head Librarian and Director of Learning Resources of the Iris Holt McEwen Library/LaRose Resources Center, Elon College, Elon College, NC.
(NCHED) survey form for The University of North Carolina and, in turn, the Higher Education General Institutional Survey (HEGIS) - now Integrated Postsecondary Education Data System (IPEDS)-form for the United States Department of Education. ${ }^{3}$ These statistics and ratios provide the basis for constructing state and national statistical norms for comparing the performance of a particular college with similar colleges in the state or the nation. ${ }^{4}$

While these statistical norms are valuable and objective data, do they really reflect the subjective value of a library collection to its user groups or the use patterns of the "average" user? For many college librarians, the answer is a resounding "no." The often neglected source for such subjective data is the opinions of the users of college libraries themselves, the vox populi-students, faculty, staff, and, in many cases nowadays, Friends of the Library. College library users in all these categories represent the internal proponent of library services and resources and a critical source of input which is often untapped.

The library survey, administered on a regularly scheduled basis, is the most effective method to gather useful data on issues of concern and trends of use among college library users. ${ }^{5}$ Although it is true that each college library is unique in terms of mission, clientele, and curriculum, there is nevertheless a vast amount of experience in the design and implementation of a library use survey that is transferable from one setting to another. Therein lies the usefulness of the often maligned case study approach and the justification for this article. ${ }^{6}$

\section{Setting for the Survey}

Elon College, a four-year private liberal arts college with master's degree programs in business administration and education, has approximately 
three thousand students, almost half of whom live on campus. ${ }^{7}$ The Iris Holt McEwen Library and LaRose Resources Center (LRC) provide resources, including over 150,000 volumes, and services to support curricular programs in over thirty academic disciplines as well as to foster independent learning among the campus community and the community at large, and to provide recreational materials for the residential student body.

In the spring of 1988 , the Head Librarian/Director of Learning Resources at Elon College together with the Faculty Library/LRC Committee explored ways to measure the effectiveness of library services and resources in preparation for an upcoming SACS reaccreditation visit. The unanimous choice of the committee was to employ the survey method to solicit the candid, confidential opinions of three types of library users: undergraduate students, graduate students, and faculty/staff.

\section{Design and Implementation of the Survey}

There was considerable discussion about the merits of survey questions eliciting short answers as opposed to those eliciting open-ended responses. After consultation with the administrative computing services office on campus, it was decided to employ a standard answer sheet which could be read by a computer but which also provided blank space for comments. Answer Sheet C, available from National Computer Systems, fulfilled these requirements. Each question elicited a short answer from up to five choices given, but respondents were encouraged to offer comments or suggestions related to any or all questions on the survey. Respondents were instructed to write their comments in the blank space provided on the answer sheet and to preface specific comments with the number of the corresponding question. The tabulation and analysis of the surveys required the use of the IBM-PC and Sentry 300 scanner for hardware and the National Computer System Microtest Score II software.

Since many potential library users never avail themselves of the services and resources provided by the library, it would have been counterproductive to survey random library users in the library itself. Also, the size of the undergraduate student population to be surveyed was problematic. The committee therefore agreed on the desirability of administering the survey to all faculty/staff and graduate students since the numbers involved were manageable, but to only a stratified random sample of the undergraduate student body.
Since the Library/LRC Committee was made up of representatives of the four major divisions of the College-Humanities, Sciences and Mathematics, Social Sciences, Teacher Education/Physical Education/Health-as well as six different disciplines-English, Education, Computer Science, History, Biology, and Psychology-the decision was made for each of the six faculty members of the committee to administer the survey to students in one of their regularly scheduled lower-level courses, primarily composed of freshmen and sophomores, and in one of their upperlevel courses, primarily composed of juniors and seniors.

... there is ... a vast amount of
experience in the design and
implementation of a library use
survey that is transferable from
one setting to another.

Each faculty member administering the survey gave a brief introduction to the survey itself, how answers were to be marked, how comments were to be made, etc. The faculty member was also available to answer questions should they arise during the survey. The same basic procedure was followed for graduate classes with the notable exception that all graduate classes were surveyed, whereas only a representative sampling of undergraduate classes was surveyed. No one took the survey more than once, however.

Each faculty/staff member was sent a form letter written by the chair of the Faculty Library/LRC Committee. The letter pointed out the rationale for the survey and particularly its importance for planning new services and improving old ones. The letter indicated that copies of the survey booklet, printed and bound by the campus print shop, and the standard, computerreadable answer sheets, as well as a tray for completed surveys, were available in a well-marked area of the mailroom. ${ }^{8}$ Since initial faculty/staff response to the survey during the first week was something less than desired, the chair made an announcement at the subsequent monthly faculty meeting that more input was needed to make the survey worthwhile.

\section{Content of the Survey}

The content of the survey engendered considerable discussion and debate with the resultant decision that questions would be framed to 
obtain background information on users and to address the following content areas: (1) library collections and availability of materials; (2) interlibrary cooperation; (3) library services; and (4) library hours and study atmosphere. Members of the Committee volunteered to submit sample questions in one or more of the four content areas. These questions were discussed at length with the result that many were combined, new questions written, and others eliminated.

In terms of background information on library users, the Committee wanted to collect data on the status of our users. Student respondents only, both graduate and undergraduate, were asked their classification; when they attended classes, whether during the day or in the evening or both; whether they lived on campus or off campus; how many hours, if any, they were employed outside of their class schedule; how many hours they were taking during the semester in question; and in which area of study they were majoring or intending to declare a major. All respondents, students as well as faculty/staff, were asked to describe their typical pattern of library use as daily, weekly, monthly, once a semester, or never; and to estimate the number of times they had already used the library during the semester in question.

\section{Perhaps the most helpful ques- tions ... were designed to deter- mine the strategies and tools library users employ to find materials or information ...}

The first content area of the survey, library collections and availability of materials, was designed to elicit the personal opinion of the respondents on the quality and quantity of resources collected by the library and, specifically, the availability of materials in various formats needed for course-related and personal or recreational use. Respondents were specifically asked how many times during the semester in question they had used circulating materials as well as reference materials restricted to library use only, and whether they usually, sometimes, hardly ever, or never found the materials they needed in the library. Respondents were polled as to their awareness and use of the government documents collection. Perhaps the most helpful questions in this area of the survey were designed to determine the strategies and tools library users employ to find the materials or information they need.
Specifically, respondents were asked if they use the card catalog, use a printed index such as Readers' Guide to Periodical Literature, use the Monthly Catalog of U.S. Government Publications, ask a librarian and/or a student assistant, read printed brochures or guides to the library, browse the Pamphlet File, browse the stacks or display areas, use a required reading list or bibliography, or do something as basic as refer to directory signs posted in the library.

Since no library has either the financial resources to purchase, or the space to house, all the materials that may be required to fulfill the research and personal information needs of users, the second section of the survey on interlibrary cooperation was essential. Elon College library users were asked if they were aware of shared borrowing privileges with member libraries of the Piedmont Independent College Association (PICA), composed of Elon College, Greensboro College, Guilford College, Bennett College, Salem College, and High Point College. Users were also asked if they were aware that other academic libraries in the area were available for reference purposes. Finally, users were asked if they were aware of the interlibrary loan service and, if so, were they satisfied with the service received.

The most critical part of the survey in terms of potential usefulness for library planning was the third section on library services. Users were asked to give their opinions on the quality of services offered including reference service from professional librarians, directional and general assistance from library student assistants, bibliographic instruction sessions, library tours and displays, and computerized database searching. Users were asked if they needed help using any of the following library resources, some of which are unique to Elon College: (1) card catalog, (2) periodicals card catalog, (3) government documents shelflist, (4) Dewey Decimal Classification, (5) indexes (e.g. Readers' Guide), (6) bibliographies (e.g. MLA Bibliography), (7) microforms, (8) computer software services (e.g. NEWSBANK), and (9) audiovisual equipment.

Since the questions of hours of opening and adequacy of study facilities loom large in the minds of college librarians, the fourth and final section on library hours and study atmosphere contained questions pertaining to the adequacy or inadequacy of the current library schedule and the arrangement and availability of study facilities and equipment including tables for group study, carrels for individual study, meeting rooms, typewriters, photocopiers, microforms readers and printers, and audiovisual equipment. Users were also 
asked to indicate which block of time they normally reserved for library study and research.

\section{Analysis and Interpretation of the Survey}

Since the first question on the survey elicits the status of the respondent, it is relatively easy to sort the surveys visually into categories and run separate analyses on target subgroups or run all respondents as a general sample. For purposes of comparison, the decision was made to try both methods of tabulation. Survey results were therefore tabulated for the following subgroups: (1) freshmen/sophomores; (2) juniors/seniors; (3) graduate students; and (4) faculty/staff as well as for the combined respondents. The corresponding numbers of respondents in each subgroup were: (1) 35 , (2) 43 , (3) 48 , and (4) 38 respectively; the combined group represented 164 respondents.

After a careful, item-by-item analysis of the survey responses, it is possible to construct a composite summary for each user group in terms of background and to compare responses in the four content areas of the survey. Most of the questions were designed so that, for purposes of analysis, responses in the $0-25 \%$ range were considered insignificant, and responses in the $75-100 \%$ range, significant. Responses in the range $26-74 \%$ could possibly represent potential area of concern.

The summaries which follow naturally reflect local conditions, but nevertheless they illustrate the types of observations that can be made from an analysis of the survey results. The ways the data can be paired and compared are almost limitless.

\section{Faculty/Staff}

Beginning with the faculty/staff, we find that this group of library users is characterized as moderate library users with eighty-nine percent responding that they used the library weekly (39\%) or monthly $(50 \%)$. Most of these users incorporate the standard strategies for finding materials ( $76-100 \%)$, and all $(100 \%)$ had used the library at least one to five times during the semester in question. Although many (74\%) use other area libraries to supplement local holdings, it is surprising that less than half $(45 \%)$ of this group have used interlibrary loan service. They use the library most heavily for reference materials with only five percent reporting that they had not used the library at least one to five times during the semester in question for these materials. This group is generally quite complimentary with regard to reference service $(71 \%)$, library tours (61\%), and library displays (74\%). Of those incor- porating bibliographic instruction sessions into their teaching, forty-two percent found them quite helpful; however, another forty-two percent have never planned a bibliographic instruction session in conjunction with a librarian. This group feels comfortable using the library as evidenced by the fact that they find the library schedule adequate for their needs $(79 \%)$, the library atmosphere conducive to study and research $(66 \%)$, and the physical layout of the library pleasing $(87 \%)$. They use the library most frequently during the regular work day, Monday-Friday, 8:00 a.m. to 5:00 p.m. (74\%) and never on Saturdays $(100 \%)$. The library facilities they use the most are the meeting rooms ( $84 \%)$, and the most popular library service is the new book shelf ( $85 \%)$.

\section{Graduate Students}

Graduate students, based on this survey, attend classes primarily in the evenings ( $81 \%$ ), live off campus (96\%), work 31-40 hours outside class $(75 \%)$, and take one $(63 \%)$ or two $(21 \%)$ classes. Their typical use pattern is weekly $(46 \%)$ or monthly (38\%). Their use of the library is heavily related to course work with sixty-nine percent responding that they never use library books for personal or recreational reading. They are not aware of PICA borrowing privileges (33\%), but are aware that other libraries are available to them for reference purposes and have taken advantage of their resources $(77 \%)$. They are either unaware of or do not use interlibrary loan service $(67 \%)$. They need help with microforms (58\%) and computer services (67\%). Most use the library at night ( $40 \%)$ and on weekends (44\%). While only fiftyfour percent find the library schedule adequate for their needs, they feel the library is conducive to study ( $85 \%$ ) and find the physical layout of the library pleasing (85\%). The library facilities used the most by graduate students are the photocopiers (69\%).

\section{... mercifully, only one percent report that they never use the library/LRC at all.}

\section{Juniors/Seniors}

The Junior/Senior sample respondents live off campus $(79 \%)$ and attend classes both during the day (53\%) and in the evening (44\%). Over half of them work 1-20 hours outside their class schedule $(52 \%)$ and are taking thirteen or more semester hours of work (63\%). They are majoring primarily in education/psychology (44\%) or mathematics/science (including computer science) 
(35\%). They use the library on a weekly $(49 \%)$ or monthly ( $40 \%$ ) basis. Most of their library use is course-related rather than for recreational purposes $(63 \%)$. Over half $(51 \%)$ have never had a bibliographic instruction session with a librarian. They use the library primarily on Monday-Thursday, 5:00 p.m. to 11:00 p.m. (51\%). While only fiftyone percent find the current library schedule adequate, most junior/senior respondents find the arrangmeent of study facilities (65\%) and the overall physical layout of the library ( $77 \%$ ) satisfactory and the library atmosphere conducive to study $(63 \%)$. They use the library mainly for quiet, individual study ( $75 \%)$ rather than group study, and use the photocopiers heavily ( $83 \%$ ).

\section{Freshmen/Sophomores.}

The freshmen/sophomore respondents attend day classes most frequently (83\%) and live on campus $(74 \%)$. They are not employed $(63 \%)$ and are taking thirteen or more semester hours of course work (89\%). They are majoring in business/economics (37\%) or education/psychology $(23 \%)$. They are weekly ( $43 \%)$ or monthly $(40 \%)$ users as a group. Their use of the library is primarily for course-related work; seventy-one percent respond that they never use books for recreational reading. They are not aware of PICA borrowing privileges $(60 \%)$ or that they may use other libraries for reference purposes (51\%). Neither are they aware of interlibrary loan service (34\%). They find the library orientation tours helpful ( $89 \%)$. Over half (51\%) have never attended or were unaware of bibliographic instruction sessions, but the forty percent who have attended one or more of these sessions rated them highly. They use the library primarily Monday-Thursday 5:00 p.m. to 11:00 p.m. ( $60 \%)$. The majority of them $(71 \%)$ find the current library schedule adequate for their needs. A substantial majority $(80 \%)$ like the study arrangement of the library and find the library atmosphere conducive to study ( $86 \%$ ). They like to study in the library in groups as well as individually (65\%), and find the physical layout of the library satisfactory (94\%).

\section{Total Respondents.}

When the combined subgroups are analyzed, the strengths and weaknesses of the library/LRC become more apparent. Library use is basically on weekly $(44 \%)$ or monthly (39\%) basis. Only six percent characterize themselves as daily users and, mercifully, only one percent report that they never use the library/LRC at all. Most of the respondents report that they use the library for course-related research and study with exactly half $(50 \%)$ reporting that they never use books from the library's collection for personal use. With regard to the satisfaction of patrons with books and periodical resources in general, eighty percent reported that the library usually or sometimes (the other two choices being hardly ever or never) had the books they needed, and seventynine percent reported the same for periodicals.

Only twenty-four percent reported that they use the government documents collection, and twenty-one percent were not aware of them at all. Since the Elon College Library has been a selective depository for government documents since 1971, here is a substantial collection which is underutilized. It is possible that since many documents are cataloged and shelved in the general stacks, library patrons may not be aware that they are indeed using government documents. However, this low use and sense of awareness seem to correlate with the fact that eighty percent do not use the Monthly Catalog as a research strategy and sixty-six percent need help with using the government documents shelflist.

\section{... there is not enough aware- ness of existing resources and services.}

While thirty-eight percent of the combined subgroups use other libraries in the area for reference purposes, ninety-three percent either do not use PICA libraries or are unaware that PICA library borrowing privileges are available to them. Significantly, only eleven percent were aware of or had used interlibrary loan service.

Reference service is quite popular, with only four percent reporting that it hardly ever meets their needs. Only five percent reported that student assistants were not helpful in providing directional and general information.

With regard to passive and active methods of bibliographic instruction, some interesting facts became apparent from a study of the survey results. While fifty-two percent of the respondents were not aware of or had not attended/planned a subject-related library seminar conducted by a librarian, the respondents who had participated in the seminars rated them highly. Library orientation tours were quite popular $(78 \%)$, whereas brochures ( $40 \%)$ and displays ( $49 \%$ ) were helpful to less than half of the respondents.

The majority of library users use the library either in the evenings during the week $(50 \%)$ or on the weekends (20\%). With regard to four critical areas of library service, the results were quite heartening. A substantial majority of the respondents found the current library schedule adequate 
for their needs ( $73 \%)$, the study arrangements in the library satisfactory ( $79 \%)$, the library atmosphere conducive to study and research $(76 \%)$, and the physical arrangement of library facilities satisfactory $(87 \%)$.

\section{Conclusions}

The Faculty Library/LRC Committee is overwhelmingly supportive of and committed to continuing its evaluation of library use utilizing the survey method. The timing of the survey during the spring semester is appropriate since most of the respondents, including the freshmen, will have been on campus and exposed to library services for at least one semester. Other sampling techniques should surely be investigated for administering the survey to a large student body, as well as additional methods planned to increase the response of faculty/staff and other populations to be surveyed totally.

It is quite apparent that while the methods of bibliographic instruction being employed by the library are sound and have been successful in teaching basic research strategies and in orienting the campus community, the subject-related library seminars are not available in the quantity that is needed to reach the majority of the library users. Efforts must be continued to incorporate bibliographic instruction into a regularly scheduled required course, preferably freshman English. Library hours, while appropriate for the majority of our users, are not adequate for the newest clientele, graduate students in business administration and education who use the library most often on the weekends. Additional staffing, however, will be required to increase the number of hours of bibliographic instruction available and the number of hours of opening on the weekends.

Throughout the survey, responses indicate that there is not enough awareness of existing resources and services. Publicity for these services and resources, notably the government documents collection, interlibrary loan, and computerbased services such as DIALOG and NEWSBANK, must be increased. Here again, when awareness is raised and demand heightens, staffing in relevant areas must be increased.

The library use survey administered at Elon College in the spring semester of 1988 will be the first in a series of attempts to gather subjective data on the value of library resources and services to library users. The fact that the survey was developed and implemented as a joint effort between the library staff and the Faculty Library/LRC Committee (representatives of one of the most serious library user groups, the faculty/staff) is assurance that results of this effort will be meaningful to a large segment of the campus community. It will be imperative in the future, however, to include students, both graduate and undergraduate, as well as Friends of the Library in the decision-making process concerning the content of the survey and in the formulation of questions.

What is clear after administering this survey is that while quantitative statistics are very important indicators of "how many" patrons are using various library resources and services, the vox populi is the source for qualitative data on "who" is using the library, "why" and "when" are they using it, and, most importantly, "what" is the degree of satisfaction obtained. College librarians must neither neglect to gather this input nor be tempted to dismiss the findings lightly if library services and resources are to be developed, maintained, improved, and otherwise seen as "good" by those who pass judgment on them.

\section{References}

1. For a complete overview of the issues of college library standards and the accreditation process, see David Kaser, "A Century of Academic Librarianship, As Reflected in Its Literature," College \& Research Libraries 37 (March 1976): 110-27 and "Standards for College Libraries," Library Trends 31 (Summer 1982): 7-19.

2. See Edward G. Holley, "New Accreditation Criteria Proposed," College \& Research Libraries News 44 (March 1983): 71-74; and the latest revision (1987) of SACS "Worksheet" for the Required Statements of the Criteria for Accreditation, " particularly Section 5.2: Library.

3. See, for example, Statistical Abstract of Higher Education in North Carolina, 1987-88 (Chapel Hill, NC: The University of North Carolina, 1988).

4. See, for example, Statistical Norms for College \& University Libraries: Derived from U.S. Department of Education 1985 Survey of College \& Research Libraries. (Boulder, CO: John Minter Associates, 1987).

5. For a humorous, but nevertheless enlightening, example of a library use survey and a particularly lively and caustic summary of the prejudices and biases librarians often have toward this type of research, see Carol Hole, "The Last User Survey You'll Ever Have To Do," The Unabashed Librarian Consecutive Number 63 (1987): 7-12.

6. Joe A. Hewitt, "The Use of Research," Library Resources and Technical Services 27 (April/June 1983): 123-31. The author agrees with Hewitt's critique of the case study approach revealed in the following passage from this article: "From the practicing librarian's viewpoint.... case study research is potentially of great usefulness because... it provides us with the basis for comparing and measuring the effectiveness of our own operations and can provide information and insight regarding management techniques to emulate or to avoid."

7. Institutional data for spring semester of 1988 published in the April 1988 issue of Second Monday: The Elon College Persomnel Newsletter.

8. Individual copies of the survey booklet are available to interested parties from Elon College Library/LRC, P.O. Box 187, Elon College, NC 27244. 

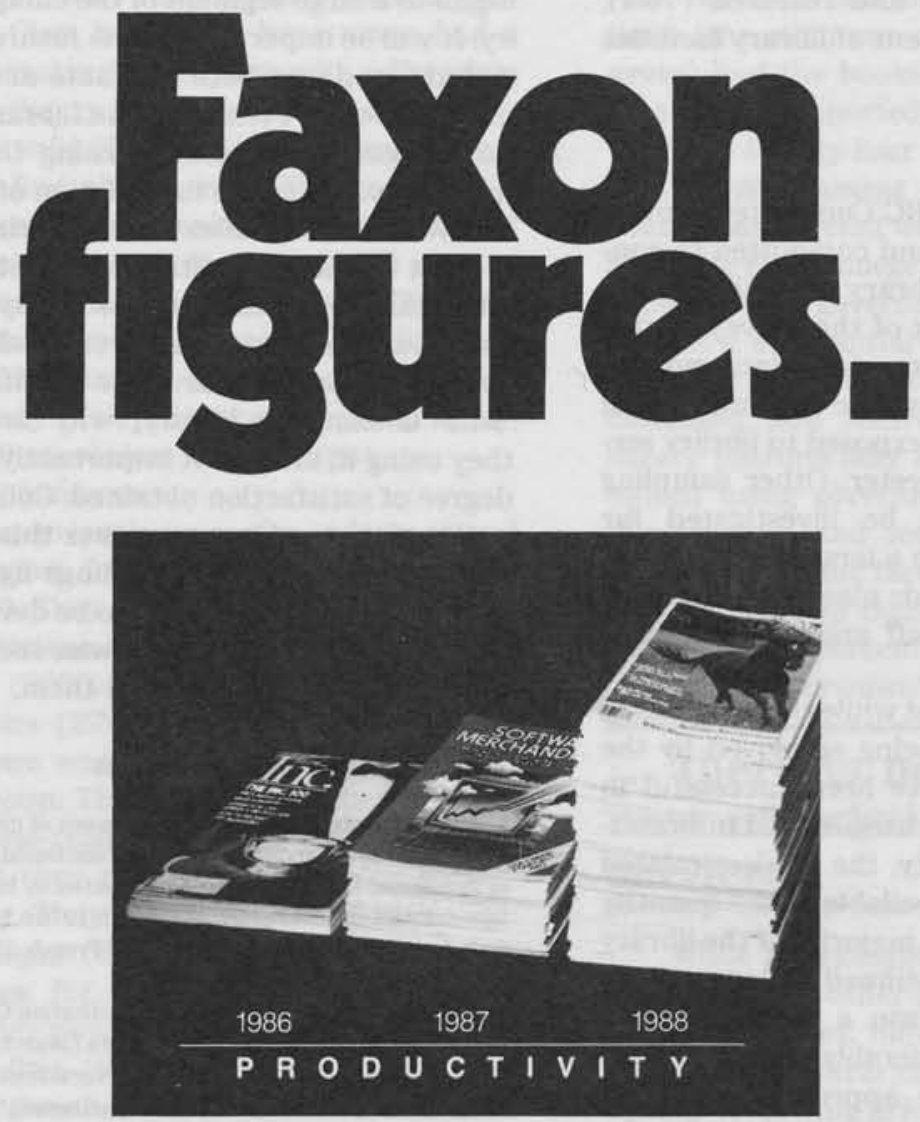

roductivity is a critical concern in today's library. That's why more and more decision makers are looking into Faxon. We can be the best source for all of your journal and continuation subscriptions. Our services enable you to devote your valuable personnel resources to other crucial library functions.

As a full service agent with access to more than 200,000 different periodicals, we can handle ordering, claiming, check-in, and routing. Our growing international network links you to other libraries, publishers, online systems, and networks.

If you can profit from improved productivity, a call to Faxon figures.

$1 \cdot 800-225-6055$

or $1.617-329-3350$ (collect)

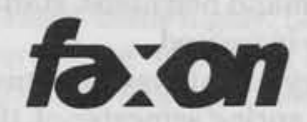

The Faxon Company 15 Southwest Park Westwood. MA 02090 